Omni-Akuatika, 12 (3): 59 - 70, 2016
ISSN: 1858-3873 print / 2476-9347 online
Research Article

\title{
Analisis Kerentanan Pulau-Pulau Kecil di Kecamatan Togean Kabupaten Tojo Una Una Provinsi Sulawesi Tengah \\ (Studi Kasus P. Kukumbi, P. Enam, P. Mogo, P. Kadidiri, P. Pagempa, P. Tongkabo)
}

\author{
Mohamad Akbar
}

\author{
*) Teknologi Penangkapan Ikan, Sekolah Tinggi Perikanan dan Kelautan Palu \\ Jalan Soekarno-Hatta km 6 (Kampus Madani) P A L U Telp/Fax (0451-4131334)
}

Corresponding author: latasad.akbar@gmail.com

\begin{abstract}
A B STRACT
This research was conducted in small islands area to Togean District, TojoUna-Una Regency Central Celebes by ecological and sosio-economic approach. Methods those used in this research were vulnerability index, MCDM (multi criteria dimension making) and Geographycal information system (SIG) approach. Data was collected bt participative and explorative approach. Data analysed parameters using vulnerability, assessment method involved vulnerability variable parameters i.e. area characteristic, area degradation, sea level rise, human impact, economic exposure, economic remoteness. The results shows the range ofcomposit vulnerability index for ecological (CVI-Ek) is $0.00-0.77$, economic (CVI-En) is $0.00-0.75$, and composite vulnerability ecological-economic (CVI-EE) is $0.00-0.76$. Enam island (0.76)and tongkabo island (0.66) is rated to high vulnerable (0.67), Mogo Island (0.14), Kukumbi Island (0.12), Pagempa Island (0.09) and Kadidiri Island (0.07), is considerednon vulnerable. MCDM analysis result that is used to determine small island management model in Togean District, shows ecological criteria is most important compared with economy criteria and social criteria. Analysis of SMART technique shows the type small islands sustainability management scenario in Togean District, those are scenario A (adaptation, 0.94) and scenario B ( without adaptation, 0.55).
\end{abstract}

Keywords : small island, composite vulnerability index, sustainability, togean district.

\section{Pendahuluan}

Pulau-pulau kecil sering diisukan sebagai suatu wilayah yang lemah atau bersifat rentan oleh faktor lingkungan, faktor ekonomi dan faktor sosial (Pratt et al.2004). Faktor lingkunganyaitu perubahan iklim dan naiknya permukaan laut; resiko gempa bumi; tsunamidan peristiwa vulkanik;ekosistem yang rapuh danketerpencilan. Faktorekonomi adalah ketergantungan eksternal yang tinggi (bantuan) dan keterisolasian lemah terhadap fluktuasi ekonomi global; peluang yangterbatas untuk penganekaragamanekonomi;pasar kecil; dasar sumberdaya kecil dan ketergantungan tinggi di sumber alam; kemampuan keuangan dan investasi rendah dan dampak yang tinggi dari ketidakstabilan politis. Faktor sosial adalah pertumbuhan populasi tinggi; migrasi dan emigrasi tinggi berkenaan dengan kota; kapasitas sumberdaya manusia yang terbatas; meningkatkan timbulnya malnutrisi, kegelisahan atau rasa tidak aman, penyakitpenyakit dan makanan; kultur dan pengetahuan tradisional.

Awal pengelolaan PPK di Indonesia dilakukan sejak berdirinya Departemen
Kelautan dan Perikanan. Setiap pulau memiliki format pengelolaan yang berbeda disesuaikan dengan latar geografisnya, karakteristik ekosistem, dan sosial budaya masyarakat setempat. Dalam arah kebijakan pengelolaan pulau-pulau yang berkelanjutan dan berbasis masyarakat, terdapat beberapa pendekatan yang dikombinasikan yaitu: (1) hak; (2) ekosistem dalam alokasi ruang wilayah pulau dan gugusan pulau; dan (3) sesuai kondisi sosial budaya setempat (Dahuri 2003). Selain memiliki potensi yang besar, pulau-pulau kecil juga mengandung potensi mudah rusak baik secara ekologi, ekonomi maupun sosial (Kaly et al. 2004).

Persoalan potensi kerusakan yang dianggap paling berbahaya adalah resiko baik secara antrophogenic ataupun secara alami. Resiko tersebut merupakan suatu kejadian yang dapat mempengaruhi integritas biologi atau kesehatan dari ekosistem. Menurut Ford (2002) pengertian kerentanan mengandung dua aspek yang terkait dengan sifatnya (relative nature) dan terkait dengan cakupan dan skala. Terkait dengan sifatnya, kerentanan adalah suatu entitas yang menggambarkan 
kondisinya, sedangkan dilihat dari skalanya, kerentanan digunakan dalam berbagai skala yang berbeda seperti rumah tangga, komunitas ataupun Negara. Kerentanan juga didefinisikan sebagai tingkat dimana sebuah sistem (dalam konteks ini pesisir dan pulau-pulau kecil sistem) akan mengalami kerugian karena terkena gangguan dan tegangan.

Konsep kerentanan yaitu kemampuan sistem untuk mengatasi dengan konsekuensi melalui strategi dan mekanisme merupakan penentu kunci dari respon sistem. Dalam kaitan tersebut, sebuah kerangka kerentanan telah diberikan oleh Turner, et.al (2002) dalam Adrianto (2004), menyatakan kerangka kerentanan terdiri dari tiga unsur penting yaitu pemaparan, kepekaan dan ketahanan. sistem Paparan berasal dari variabilitas dan perubahan pada kondisi manusia serta lingkungan dan alam. Perubahan ini mengakibatkan gangguan dan tegangan yang dianggap sebagai parameter kunci dari pantai/pulau eksposur. Sistem berikutnya adalah sensitivitas sistem yang terkait dengan keragaman sosial-ekonomi serta kondisi biofisik dari sistem pesisir. Akhirnya, sistem ketahanan berkaitan dengan tanggapan sistem yang bergantung pada kemampuan sistem untuk mengadopsi dampak dan dalam waktu yang sama untuk mengelola resiko yang dihasilkan.

Peeling dan Uioto (2001) 6 faktor yang mempengaruhi tingkat kerentanan pulau-pulau kecil yaitu : 1) ukuran (luasan) yang kecil berimplikasi pada keterbatasan sumberdaya berbasis daratan; 2) terisolasi dan terpencil yang berimplikasi pada biaya yang mahal dan memerlukan waktu yang lebih lama; 3) masalah faktor lingkungan seperti ketersingkapan terhadap gangguan; 4) kapasitas mitigasi terhadap bencana yang terbatas; 5) faktor penduduk yang memiliki kualitas sumberdaya manusia yang rendah, tingkat pertumbuhan penduduk yang tinggi ; 6) faktor ekonomi seperti ketergantungan pada pembiayaan eksternal, pasar internal yang terbatas.

Berkaitan dengan uraian di atas maka untuk kepentingan pengelolaan lingkungan dan sumberdaya pesisir Kepulauan Togean, perlu dikaji secara baik sehingga tindakan-tindakan pengelolaannya dapat bermanfaat secara baik dan berkelanjutan. Untuk mendefinisikan rencana strategi yang tepat dan akurat guna pengembangan PPK di Gugus Pulau Togean perlu dilakukan kajian kerentanan (vulnerability) dan menyusun strategi pengelolaan PPK berkelanjutan.Tujuan umum dari penelitian ini yaitu : (1) mengestimasi tingkat kerentanan masing-masing PPK; (2) memetakan tingkat kerentanan PPK Gugus Pulau Togean secara spasial dengan metode cell based modeling;(3) menyusun strategi pengelolaan pembangunan PPK gugus Pulau Togean.

\section{Metodologi}

\section{Waktu dan lokasi penelitian}

bulan mulai bulan Maret sampai September2011 yang terdiri dari pengumpulan data awal, Pengolahan data awal, survei lapangan dan proses pengolahan data lanjutan. Lokasi penelitian di wilayah administrasi Kabupaten Tojo Una-Una Provinsi Sulawesi Tengah yang meliputi pulau-pulau kecil (PPK) yang berada di dalam Gugus Pulau Togean (Gambar 1).

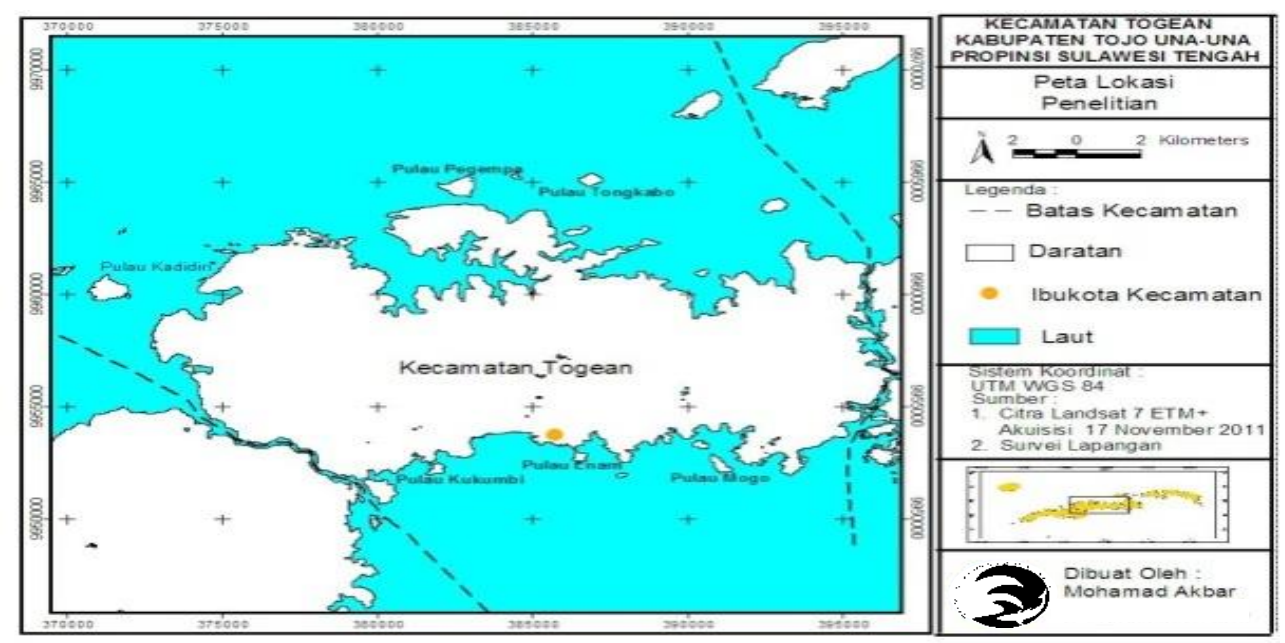

Gambar 1. Lokasi penelitian 


\section{Jenis dan sumber data}

Jenis data yang dikumpulkan dalam penelitian ini berupa data primer maupun data sekunder. Pengambilan data primer dan sekunder meliputi data-data ekologi dan ekonomi pada setiap pulau. Metode yang digunakan adalah metode survei dengan tujuan untuk membuat suatu gambaran secara sistematis mengenai fakta-fakta serta hubungan antara fenomena yang diteliti. metode ini di bagi ke dalam tiga kelompok yaitu (1) memberikan gambaran situasi atau suatu kejadian; (2) menerangkan hubungan antar peubah-peubah; (3) pengumpulan data dilakukan dengan cara wawancara terhadap responden. Data sekunder meliputi data dari

Tabel 1. Indek Kerentanan Ekologi

\begin{tabular}{|c|c|c|c|}
\hline Indeks & Rumus & & Keterangan \\
\hline \multirow{6}{*}{$\begin{array}{c}\text { Indeks Pantai (Coastal } \\
\text { index) }\end{array}$} & & $\mathrm{Cl}$ & $=$ Indeks Pantai \\
\hline & $C L_{i}=\frac{L_{i}}{2}$ & $\mathrm{Li}$ & $=$ Panjang Garis Pantai $(\mathrm{Km})$ \\
\hline & & $\mathrm{Ai}$ & $=$ Luas Pulau $\left(\mathrm{Km}^{2}\right)$ \\
\hline & & I & = Nama PPK \\
\hline & & II & = Insularity Index \\
\hline & & $\begin{array}{l}S_{i j} \\
1\end{array}$ & $\begin{array}{l}=\text { jarak PPK i dengan } \\
\text { PPK/Mainland J }\end{array}$ \\
\hline \multirow{4}{*}{$\begin{array}{l}\text { Indeks Keterisolasian } \\
\text { (Insularity Index) }\end{array}$} & & & $=$ Mewakili jarak PPK i dengan \\
\hline & $I I_{i}=\sum_{j=1}^{5} \sqrt{S_{i j}}$ & 2 & $\begin{array}{l}\text { PPK lainnya yang seukuran } \\
\text { atau lebih besar terdekat } \mathrm{j} \\
=\text { Mewakili jarak PPK } \mathrm{i} \text { dengan }\end{array}$ \\
\hline & & 3 & Mainland-1 j \\
\hline & & & $\begin{aligned}= & \text { Mewakili jarak PPK i dengan } \\
& \text { Mainland-2 j }\end{aligned}$ \\
\hline \multirow{3}{*}{$\begin{array}{l}\text { Indeks Degradasi Lahan } \\
\text { Terbangun (DLT) }\end{array}$} & \multirow{3}{*}{$D L T=\frac{L T_{i}}{A_{i}} \times 100$} & $\mathrm{Cl}$ & = Degradasi Lahan Terbangun \\
\hline & & $\begin{array}{l}\mathrm{LT} \\
\mathrm{Ai}\end{array}$ & $\begin{array}{l}(\%) \\
=\end{array}$ \\
\hline & & & $\begin{array}{l}=\text { Luas PPK }\left(\mathrm{Km}^{2}\right) \\
=\text { Nama PPK }\end{array}$ \\
\hline \multirow{3}{*}{$\begin{array}{l}\text { Indeks Degradasi } \\
\text { Mangrove (Dmrv) }\end{array}$} & \multirow{3}{*}{$D M r v_{i}=\frac{L M r v_{i, t 1}}{L M r v_{i, t 0}} \times 100$} & DMrv & = Degradasi Tutupan Mangrove \\
\hline & & $\begin{array}{l}\text { LMrv } \\
t_{0}\end{array}$ & $\begin{aligned} & (\%) \\
= & \text { Luas Tutupan Mangrove }\left(\mathrm{Km}^{2}\right)\end{aligned}$ \\
\hline & & & $\begin{array}{l}=\text { Tahun Awal } \\
=\text { Tahun Akhir }\end{array}$ \\
\hline \multirow{3}{*}{$\begin{array}{c}\text { Indeks Degradasi } \\
\text { Terumbu Karang (DTK) }\end{array}$} & \multirow{3}{*}{$D T K_{i}=\frac{L K m_{i}}{L T K_{i}} \times 100$} & $\begin{array}{l}\text { DTK } \\
\text { LKm }\end{array}$ & $\begin{array}{l}=\text { Degradasi Tutupan Karang } \\
(\%)\end{array}$ \\
\hline & & LTK & $=$ Luas Tutupan Karang Mati \\
\hline & & & $\begin{aligned} & \left(\mathrm{Km}^{2}\right) \\
= & \text { Total Luas Tutupan Karang } \\
& \left(\mathrm{Km}^{2}\right) \\
= & \text { Nama PPK }\end{aligned}$ \\
\hline \multirow{4}{*}{$\begin{array}{c}\text { Indeks Sea Level Rise } \\
\text { (SLR) }\end{array}$} & \multirow{4}{*}{$S L R_{i t}=\frac{P V(S L R)_{i t}}{G I P_{i T}} \times 100$} & $\begin{array}{l}\text { SLR } \\
\text { PV }\end{array}$ & $\begin{array}{l}=\text { Degradasi Tutupan Karang } \\
(\%)\end{array}$ \\
\hline & & $(\mathrm{SLR})_{\mathrm{it}}$ & $=$ Nilai Estimasi dampak SLR \\
\hline & & & $\begin{array}{l}\text { terhadap nilai manfaat Gros } \\
\text { Island Product (GIP) PPK i } \\
\text { pada Tahun t }\end{array}$ \\
\hline & & $\mathrm{GIP}_{\text {it }}$ & $\begin{array}{l}=\text { Total GIP dasar Pulau i Pada } \\
\text { Tahun } t\end{array}$ \\
\hline
\end{tabular}

berbagai sumber yang berkaitan dengan informasi terhadap penelitian ini seperti DISKANLUT, BAPEDALDA Kabupaten Tojo Una-Una, BPS dan Lembaga Swasta terkait yang ada dalam Pemerintahan Kabupaten Tojo Una-Una.

Analisis data

\section{Kerentanan ekologi}

Untuk melihat kerentanan ekologi PPK didasarkan pada gabungan beberapa indeks ekologi yaitu indeks pantai $(\mathrm{Cl})$, indeks keterisolasian (II), indeks degradasi lahan terbangun (DLT), indeks degradasi mangrove (DMRv), indeks degradasi terumbu karang (DTK), indeks sea level rise (SLR) (Tabel 1). 


\section{Kerentanan ekonomi}

Kerentanan ekonomi akan menggunakan beberapa indeks yaitu indeks populasi (Popl), indeks Keterbukaan Ekonomi dan Indeks Keterpencilan Ekonomi (Tabel 2).

Tabel 2. Indeks Kerentanan Ekonomi

\begin{tabular}{|c|c|c|c|}
\hline Indeks & Rumus & & Keterangan \\
\hline indeks populasi (Popl) & PopI $=\left(\left(\frac{N A_{i t}}{50}\right) x\left(\frac{\text { Trend }_{i, t-1}}{2}\right)\right)$ & $\begin{array}{l}\text { Popl } \\
\mathrm{NA}_{\text {it }} \\
\mathrm{Ai} \\
\text { Trend }_{\mathrm{i}, \mathrm{t}-1} \\
50 \text { dan } \\
2\end{array}$ & $\begin{aligned}= & \text { Indeks Populasi } \\
= & \text { Rata-Rata populasi per } \\
& \mathrm{Km}^{2} \text { PPK i pada Tahun } \mathrm{t} \\
= & \text { Pertumbuhan Populasi } \\
& \text { per Tahun pada PPK i } \\
= & \text { Konstanta }\end{aligned}$ \\
\hline $\begin{array}{l}\text { Indeks Keterpencilan } \\
\text { Ekonomi (Economic } \\
\text { Remotness, ER) }\end{array}$ & $\begin{array}{l}\text { 1. Perdagangan Eksternal } \\
E T_{i t}=\frac{M_{i t}+X_{i t}}{2 N V_{i t}} \times 100\end{array}$ & $\begin{array}{l}\text { ER }_{\text {it }} \\
\text { TTC }_{\text {it }} \\
\text { GIP }_{\text {tr, it }} \\
2 N V\end{array}$ & $\begin{aligned} &= \text { External Trading } \\
& \text { (Perdagangan } \\
& \text { Eksternal) } \\
&= \text { Total nilai perdaangan } \\
& \text { Inflow PPK i pada } \\
& \text { Tahun } \mathrm{t} \\
&= \text { Total nilai perdaangan } \\
& \text { Outflow PPK i pada } \\
& \text { Tahun } \mathrm{t} \\
&= \text { Nilai valuasi } \\
& \text { (Ekosistem) dari PPK i } \\
& \text { pada Tahun } \mathrm{t} \\
&=\text { In } \rho \text { Konstanta } \\
&=\text { Nilai Elastisitas } \\
&= \text { Produk domestik bruto } \\
& \text { PPK i pada tahun } \mathrm{t} \\
&= \text { Jumlah tunjangan yang } \\
& \text { diterima oleh PPK i } \\
& \text { pada tahun } \mathrm{t} \\
&= \text { Economic Remotness } \\
&= \text { Total Biaya } \\
& \text { Transportasi Pulau } \\
& \text { Kecil (Rupiah/Unit } \\
& \text { Modal) } \\
&= \text { GIP sektor transportasi } \\
& \text { untuk PPK i pada tahun } \\
& \mathrm{t} \\
&= \text { Nilai valuasi } \\
& \text { (Ekosistem) dari PPK i } \\
& \text { pada Tahun t }\end{aligned}$ \\
\hline
\end{tabular}

Standarisasi dan komposit indeks kerentanan

Standarisasi dan komposit indeks kerentanan adalah sebagai berikut :

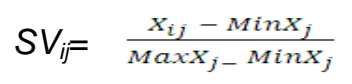

$$
\left(0<S V_{i j}<1\right)
$$

$\mathrm{j}=C I, I I, D L T, D M r v_{i}, D T K_{i}, S L R_{i}, P o p l, E T_{i}$, $E F_{i,} E r_{i}$

Pada penelitian ini, masing-masing tujuan komposit indeks kerentanan (CVI) dibuat atau disusun secara additif dan multiplikatif sebagai berikut :

a) Komposit indeks kerentanan ekologi (CVI-Ek) PPK

b) Komposit indek kerentanan ekonomi (CVI-En) PPK

c) Komposit indek kerentanan ekologi-ekonomi (CVI-EE) PPK

$\mathrm{CVI}(\mathrm{EE})_{\mathrm{i}}=\left(\mathrm{CVI}(\mathrm{Ek})_{\mathrm{i}} \times 0,6\right)+(\mathrm{CVI}$

(En) $\times 0,4)$ 
Keterangan :

$\mathrm{CVI}(\mathrm{EE})$ : Komposit indeks kerentanan ekologiekonomi PPK i

$\mathrm{CVI}(E \mathrm{k})_{\mathrm{i}}$ : Komposit indeks kerentanan ekologi PPK i;

CVI(En)i : Komposit indeks kerentanan ekonomi PPK i;

0.6, 0.4 : Bobot pertimbangan pada masingmasing $\mathrm{CVI}(\mathrm{Ek})_{\mathrm{i}}$ dan $\mathrm{CVI}(\mathrm{En})_{\mathrm{i}}$

Penentuan tingkat kerentanan

Pada penelitian analisis kerentanan di Gugus Pulau Togean, mengambil model perpaduan di atas dengan memanfaatkan nilai kerentanan kuantitatif dari Briguglio (1995); Adrianto and Matsuda (2002;2004) dengan membagi sesuai banyaknya tingkatan sifat Tabel 2. Penentuan tingkat kerentanan PPK kerentanan (kuantitatif) dari Kaly et al. (2004). Metode ini dikembangkan berdasarkannilai standarisasi dari variabel yang ada didalamnya, pembobotan atau beban dari masing-masing potensi dampak tekanan (pressure), mengakomodir perubahan nilai tekanan exogenous dimasa mendatang dan relatif lebih mudah dalam melakukan penilaian tingkat kerentanan suatu lokasi dengan memanfaatkan ketersediaan serta tingkat pentingnya dari indikator yang sering kali perolehannya terbatas, sehingga untuk penggunaan metode statistik kurang relevan dengan situasi lokasi studi dan juga pertimbangan kemudahan dengan penggunaan metode GIS. Adapun pembagianlevel kerentanan terlihat pada Tabel 2.

\begin{tabular}{ccc}
\hline Nilai CVI & Level Kerentanan & Indikator Warna Level \\
\hline $0.0 \leq \mathrm{CVI} \leq 0.2$ & Non-vulnerable & Hijau \\
$0.2 \leq \mathrm{CV} \mid \leq 0.4$ & Low Vulnerable & Biru \\
$0.4 \leq \mathrm{CV} \mid \leq 0.6$ & Medium vulnerable & Kuning \\
$0.6 \leq \mathrm{CV} \mid \leq 0.8$ & Highly vulnerable & Merah Muda \\
$0.8 \leq \mathrm{CVI} \leq 1.0$ & Extremely vulnerable & Merah \\
\hline
\end{tabular}

Sumber : Hasil pengembangan dari gabungan metode Briguglio (1995); Adrianto and Matsuda (2004) dengan metode Kaly et al. (2004)

\section{Pengolahan citra satelit}

Citra diperlukan untuk mengestrak datadata yang berkaitan dengan fenomena dampak exogenous yang terjadi di masing-masing ekosistem utama di PPK dalam kurun waktu tertentu seperti luas lahan terbangun, luas tutupan karang dan luas tutupan mangrove. Selain itu juga data fisik pulau berupa luas, panjang garis pantai dan jarak antar pulau/mainland, serta sebagai bahan dalam pembuatan peta kerentanan secara digital. Bahan-bahan citra yang diperoleh masih memerlukan pengelolaan secara digital dengan menggunakan software ER Mapper 6.4 dan ArcView GIS 3.3 pada komputer, sehingga diperoleh hasil yang diinginkan.

\section{Analisis multi kriteria}

Tahapan-tahapan dalam analisis MCDM dengan menggunakan teknik SMART (simple multi attribute rating technique) yaitu :(1) menentukan kriteria dan alternatif yang digunakan dalam pengelolaan SDL di Wilayah GPT; (2) menyusun struktur hirarki pengelolaan SDL di wilayah GPT, mulai dari tujuan pengelolaan, kriteria, sub kriteria sampai pada alternatif yang relevan dalam pengelolaan SDL di wilayah GPT;(3) menentukan pengukuran numerik (bobot) terhadap kriteria, sub kriteria dan alternatif; 4) Faktor yang menjadi pertimbangan penentuan prioritas pengelolaan sumberdaya laut di wilayah Gugus Pulua Togean dilakukan dengan menggunakan metode scoring atau pembobotan yang merupakan penyatuan dari berbagai parameter terkait. Skor yang digunakan untuk penilaian elemen-elemen yang diteliti, dinyatakan secara numerik (skala 1 hingga 9) dengan menggunakan skala Saaty (1991).

\section{Hasil dan Pembahasan}

\section{Kerentanan ekologi}

Hasil kerentanan ekologi dan peta kerentanan ekologi terlihat pada Gambar 2 dan Gambar 3.

Untuk indeks pantai yang tertinggi adalah $P$. Enam dan terendah $P$. Kadidiri.Indeks pantai menggambarkan bentuk dan ukuran pulau tersebut, dimana pulau yang memiliki nilai indeks tertinggi merupakan pulau yang memiliki banyak lekukan (teluk) dan ukurannya lebih kecil.Dalam kaintannya dengan konteks kerentanan ekologi, PPK yang memiliki ukuran luas lebih kecil lebih bersifat 
rentan oleh dampakexogenous, baik secara alami maupun atropogenik (kaly et al. 2004; Beller et al. 1990; Briguglio 1995; Adrianto and Matsuda 2004).

Indeks keterisolasian merupakan suatu indeks yang mencerminkan sifat kedudukan pulau terhadap daratan lainnya yang lebih dekat dan berukuran lebih besar. PPK yang umumnya memiliki banyak keterbatasan kaitannya dalam lahan yang ditengah lautan yang lebih luas, merupakan suatu kondisi yang mengandung banyak resiko dan kerugian oleh tekanan maupun goncangan faktor luar (exogenous), baik yang bersifat alami maupun antropogenik.Semakin tinggi nilai indeks keterisolasian suatu pulau berarti pulau tersebut semakin terisolasi.Indeks keterisolasian yang tertinggi $P$. Tongkabo dan terendah $\mathrm{P}$. Enam.

Salah satu konsekuensi kehadiran tekanan populasi di PPK adalah Pemenuhan atas pemanfaatan ruang pulau seperti kebutuhan lahan perumahan dan lainnya.Indeks degradasi lahan terbangun yang tertinggi pada $\mathrm{P}$. Tongkabo dan terendah $\mathrm{P}$. Mogo, P. Kukumbi, P. Pagempa dan P. Kadidiri. Terbatasnya lahan yang merupakan karakteristik umum secara fisik dan tingginya ukuran populasi penduduk PPK, akan meningkatkan dampak tekanan populasi terhadap lingkungan pulau Tongkabo dan $P$. Enam. Pada P. Tongkabo penggunahan lahan masih terpusat pada pulau tersebut, akan tetapi pada pulau enam yang memiliki bentuk fisik berbukit, sehingga msayarakat menggunakan lahan perairan. Dalam konteks kerentanan penggunaan lahan perairan dianggap sebagai degradasi lahan.

Terjadinya degradasi terumbu karang merupakan salah satu pembuktian yang kuat dari adanya tekanan populasi yang ada di PPK.Indeks degradasi terumbu karang yang tertinggi pada P. Pagempa dan P. Tongkabo dan terendah $P$. Kadidiri.Walaupun hanya sekitar setengah dari jumlah PPK di kecamatan togean yang berpenduduk bahkan beberapa PPK tidak berpenduduk seperti (P. Kukumbi, P. Mogo) namun degradasi terumbu karang yang berada didaerah tersebut cukup tinggi. Saling berdekatannya PPK yang ada di Kecamatan Togean, sehingga walaupun beberapa pulau tidak berpenduduk tetap akan menjadi bagian wilayah penangkapan ikan dan pemanfaatan lainnya bagi masyarakat yang berada didekatnya.

Sumberdaya lainnya yang juga mengalami degradasi yaitu mangrove. Eksploitasi yang dilakukan oleh masyarakat di PPK umumnya untuk memenuhi kebutuhan masyarakat sekitarnya seperti kayu bakar, bahan bangunan, bahan bantu alat penangkapan ikan, dan juga kulit mangrove yang digunakan masyarakat setempat sebagai bahan pewarna untuk perahu serta lahan mangrove yang dikonversi sebagai lahan permukiman.Indeks degradasi mangrove yang tertinggi adalah $\mathrm{P}$. Enam dan terendah $\mathrm{P}$. Kadidiri.

Nilai indeks kenaikan muka laut yang merupakan index natural disaster memperlihatkan terdapat dua buah PPK yang memiliki proyeksi terkena dampak kenaikan muka laut yang cukup tinggi yaitu P. Enam dan P. Tongkabo.

Nilai dampak SLR terhadap satuan luas lahan pulau P. Enam jauh lebih tinggi dibandingkan dengan P. Tongkabo. Perbedaan ini berkaitan dengan ukuran fisik pulau dimana P. Enam jauh lebih Kecil dibanding dengan ukuran P. Tongkabo. Selain itu juga dipengaruhi oleh laju pertmbuhan GIP sehingga memicu naiknya nilai riel (reel value, $\mathrm{RV}$ ) dan nilai manfaat (present value, PV) dari GIP dan GIP-P.

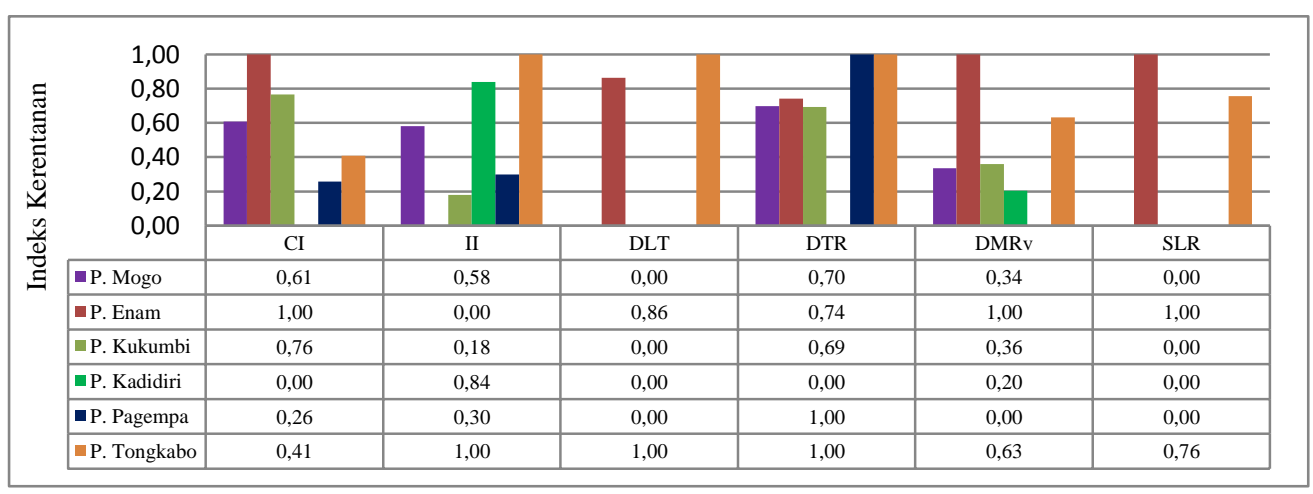

Gambar 2. Komposit indeks kerentanan ekologi 


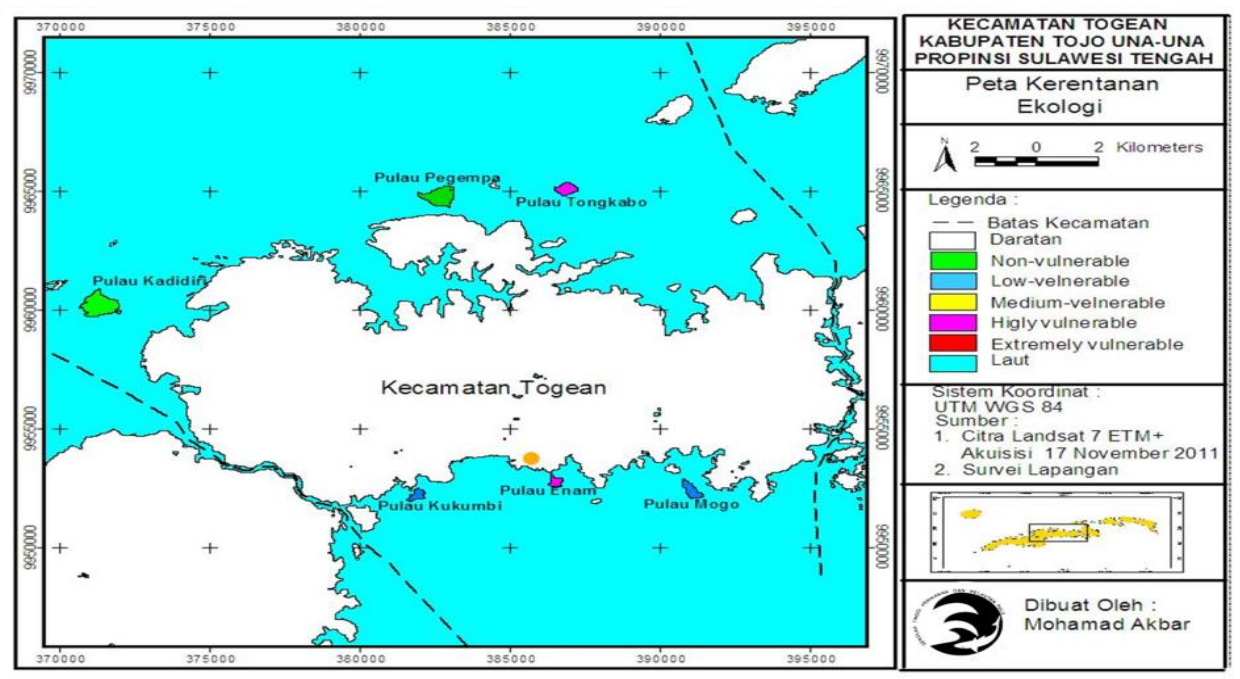

Gambar 3. Peta kerentanan ekologi

\section{Kerentanan ekonomi}

Hasil kerentanan ekonomi dan peta kerentanan ekonomi masing-masing PPK terlihat pada Gambar 4 dan Gambar 5.

Keahadiran manusia pada suatu pulau memberikan dampak dan tekanan bagi lingkungan, dimana pemanfaatan lingkungan dan potensi sumberdaya PPK guna memenuhi kebutuhan. Masalah yang akan terjadi bila pemanfaatan potensi sumberdaya PPK dan lingkungan tidak dilakukan secara berkelanjutan yang akan menyebabkan PPK tersebut koleps.

Hasil indeks populasi yang tertinggi adalah P. Enam dan diikuti oleh P. Tongkabo.Untuk PPK lainnya tidak berpenghuni sehingga indeks populasinya sangat rendah. Menilai keterbukaan ekonomi masing-masing PPK merujuk pada rasio aktivitas perdagangan eksternal (ET) untuk mencerminkan tingkat keterbukaan pulau (Briguglio 1995) dan juga dari rasio keuangan eksternal (EF) untuk mencerminkan tingkat ketergantungan keuangan pada pemerintah atau institusi luar (Briguglio 1995; Adrianto and Matsuda 2004).

Nilai $E T$ yang tertinggi pada $P$. Enam dan terendah P. Mogo, P. Kukumbi, P. Kadidiri, $P$. Pagempa dan $P$ Tongkabo. Nilai $E T$ mencerminkan kemampuan pasar, dimana semakin tinggi nilai ET menandakan kemampuan pasar di dalam PPK tersebut sangat rendah. Hasil ini sejalan dengan Briguglio (1995) dan Adrianto (2005), menyatakan bahwa PPK memiliki pasar domestik yang kecil dan ketergantungan terhadap ekspor untuk menggerakkan ekonomi pulau.

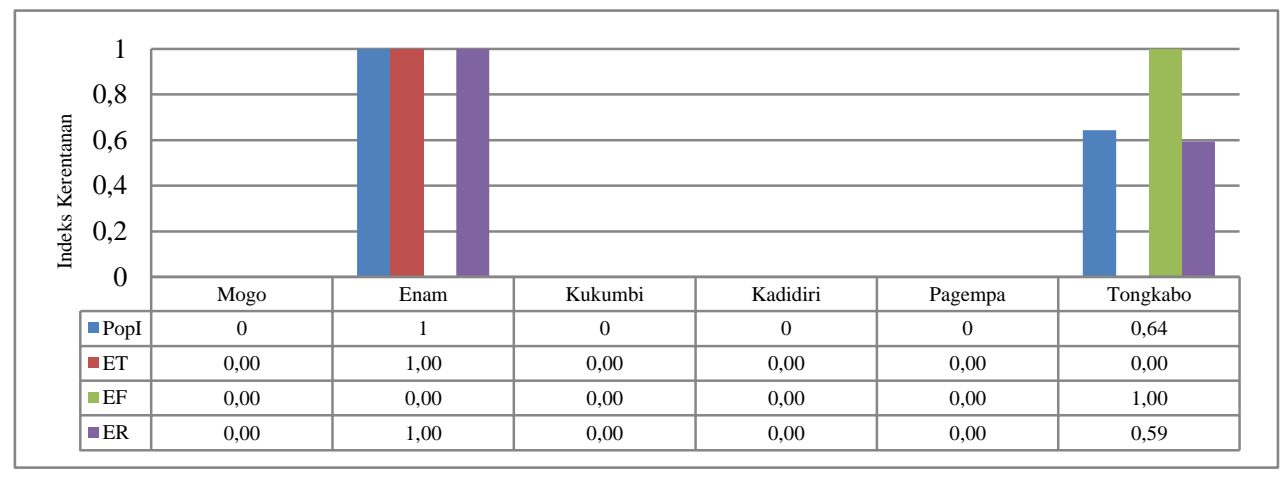

Gambar 4.Komposit indeks kerentanan ekonomi 


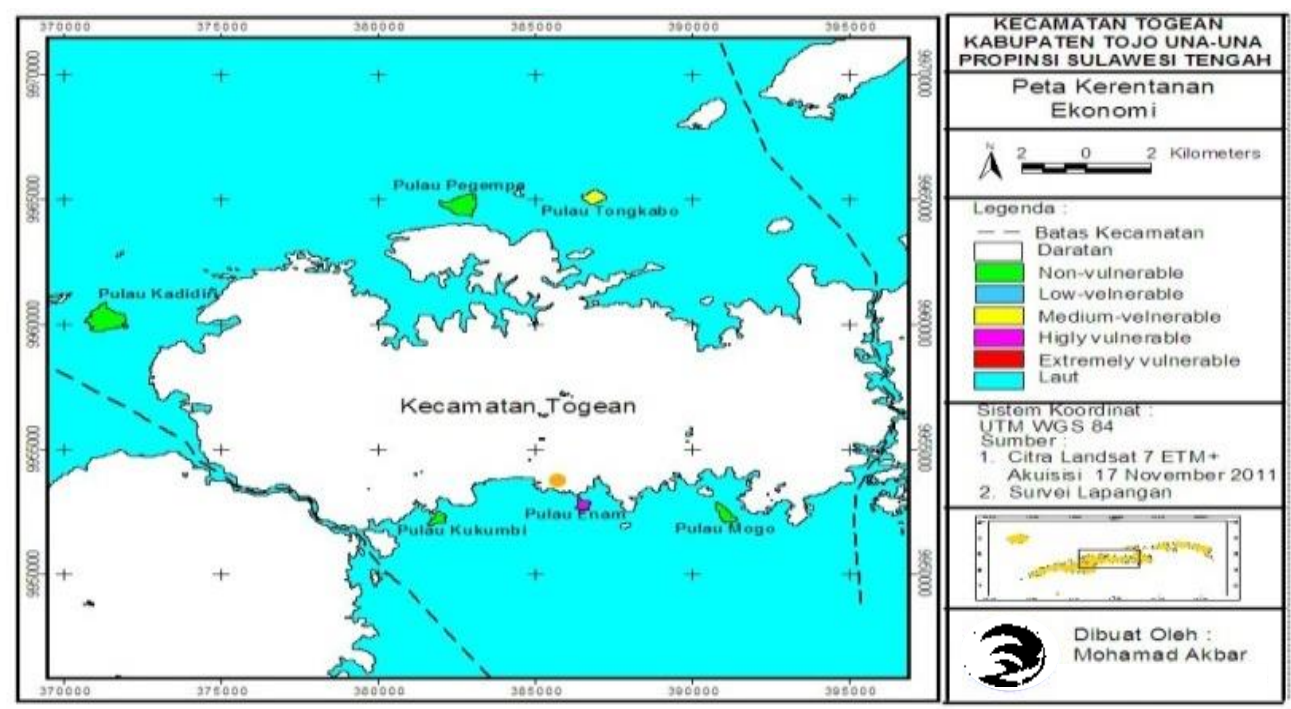

Gambar 5. Peta kerentanan ekonomi

EF yang tertinggi pada $P$. Tongkabo hal ini bermaksud $P$. Tongkabo memiliki ketergantungan tunjangan pemerintah yang sangat besar dibandingkan dengan PPK lainnya.

Keterpencilan selalu dikaitkan dengan pemahaman yang berhubungan dengan permasalahan kedudukan atau wilayah (Hein 1990; Conley dan Ligon 1998; Cros dan Nutley 1999). Keterpencilan ekonomi terhadap suatu pulau dihubungkan dengan kerentanan dari segi ekonomi, dimana berkaitan dengan ketidakpastian suatu keadaan bagi keterlambatan dan biaya dalam perdagangan eksternalnya (Briguglio 1995; Adrianto dan Matsuda 2004).

PPK dalam gugus Pulau Togean, umumnya belum memiliki sistem transportasi yang lancar. Presentase ER terhadap total pendapatan domestik bruto pulau sektor transportasi $\left(\mathrm{GIP}_{t r}\right)$ memperlihatkan Presentase ER tertinggi adalah P. Enam (Kerentanan Ekstrim)dan diikuti dengan $P$. Tongkabo (Kerentanan sedang).Hal ini disebabkan oleh faktor jarak dan skala angkutan yang memerlukan jasa transportasi dari dan ke PPK tersebut menjadi penyebab tingginya biaya satuan angkutan barang dan orang. Masingmasing PPK tersebut memiliki ciri, dimana P. Enam lokasinya jauh dari mainland-1 dan mainland-2, skala volume angkutan yang rendah dan posisinya jauh dari alur transportasi laut yang agak ramai. Sedangkan P. Tongkabo lebih berkaitan dengan skala volume angkutan yang rendah. Selain menitik beratkan pada eksistensi lahan dan ekosistem pulau yang secara fisik (luas, bentuk, kedudukan), namun dalam konteks kerentanan ekonomi dampak dari variable kerentanan ekonomi lebih tergantung dari ada dan tidaknya aktivitas perekonomian di lahan PPK tersebut. PPK yang tidak memiliki penduduk atau tidak adanya aktivitas perekonomian dianggap tidak ada dampak oleh variable kerentanan ekonomi (indeks bernilai nol).

\section{Komposit indeks kerentanan ekologi-ekonomi}

Komposit indeks kerentanan ekologiekonomi merupakan gabungan dari komposit indeks kerentanan ekologi dan komposit indeks kerentanan ekonomi. Perbandingan nilai CVIEE dengan nilai CVI-Ek dan CVI-En yaitu nilai CVI-EE lebih kecil dibandingkan dengan nilai CVI-Ek dan sebaliknya nilai CVI EE lebih Besar dibandingkan dengan nilai CVI-En (CVI Ek > CVI EE > CVI En). Tingkat kerentanan pada masing-masingPPK (CVI-EE)disajikan dalam Gambar 6 dan Peta kerentanan gabungan Ekologi-Ekonomi masing-masing PPK terlihat dalam Gambar 7. 


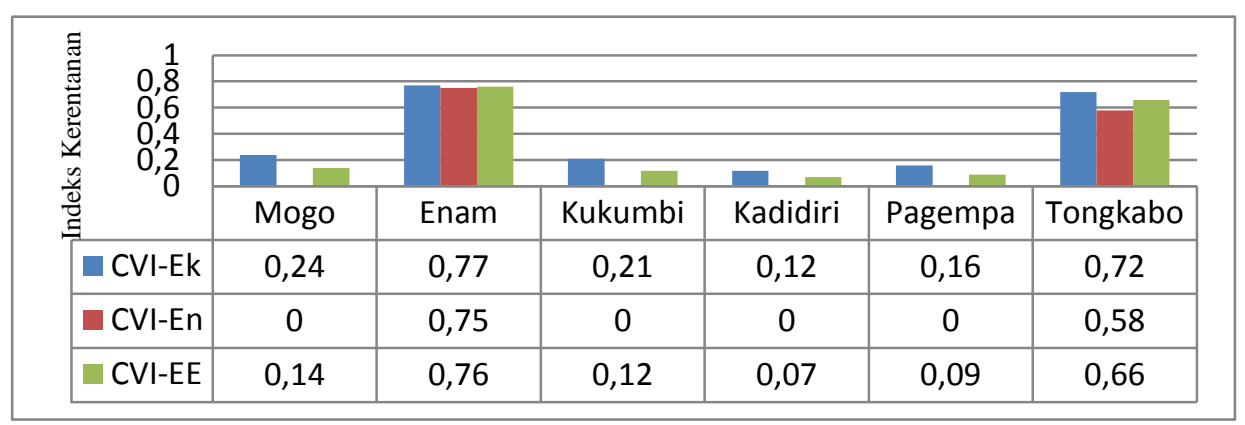

Gambar 6. Komposit indek kerentanan PPK

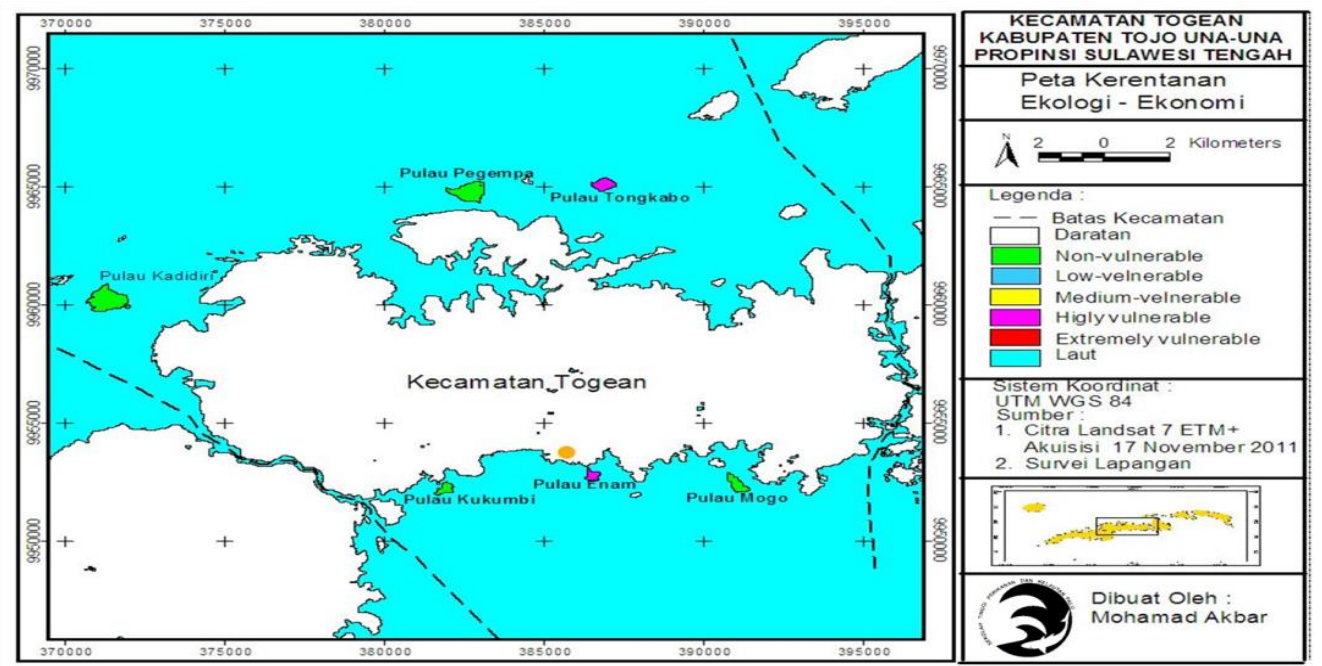

Gambar 7. Peta kerentanan PPK Kecamatan Togean

Hasil penentuan dan pemetaan kerentanan ekologi-ekonomi, terlihat bahwa $P$. Enam dan P. Tongkabo masuk ke dalam level high-vulnerable, sedangkan P. Mogo, P. Kukumbi, P. Pagempa dan P. Kadidiri masuk Ke dalam Level non-vulnerable.

Perbedaan karakteristik dari masingmasing PPK berimplikasi kepada level kerentanan yang berbeda, dimana pulau yang berukuran lebih kecil memiliki nilai kerentanan ekologi-ekonomi yang lebih tinggi, disamping itu pula adanya faktor dampak kerentanan dari tekanan populasi yang terjadi pada masingmasing PPK. Karakteristik sifat smallness, akan mengurangi kemampuan ketahanan PPK dalam hal meredam dampak-dampak secara eksternal, baik secara alami maupun faktor antropogenik. Sifat remoteness merupakan penghalang yang besar terhadap percepatan dan keberlanjutan pembangunan PPK ke depan.

Pulau Enam merupakan pulau yang memiliki tingkat kerentanan yang sangat ekstrim baik dilihat dari ekologi, ekonomi maupun gabungan ekologi-ekonomi. Kecilnya ukuran fisik pulau dan densitas penduduk yang cukup tinggi dan relatif jauh dari mainland (Jalur pelayaran) membuat tekanan faktor eksogonous baik alami maupun atropogenik jauh lebih tinggi dibandingkan dengan PPK lainnya. PPK lainnya yang kerentanan ekologi, ekonomi maupun gabungan ekologi-ekonomi (CVI-EE) tergolong ke dalam level high vulnerable yaitu $\mathrm{P}$. Tongkabo. Walaupun $\mathrm{P}$. Tongkabo jaraknya dengan mainland lebih jauh dibandingkan dengan P. Enam, akan tetapi P. Tongkabo berada di jalur pelayaran sehingga distribusi barang dan jasa akan lebih mudah.

Sedangkan untuk P. Kukumbi dan P. Mogo walaupun nilai kerentanan ekologi-ekonomi yang termasuk ke dalam level non-vulnerable, akan tetapi kerentanan ekologi masuk ke dalam level low-vulnerable, hal ini mengindikasikan bahwasannya walaupun pulau tersebut tidak berpenghuni akan tetapi pemanfaatan dari segi ekologi oleh masyarakat yang berada dekat dengan pulau tersebut sangat tinggi. Sedangkan untuk P. Pagempa dan P. Kadidiri tergolong ke dalam level nonvulnerablebaik dari segi ekologi, ekonomi maupun gabungan ekologi-ekonomi. 


\section{Skenario pengelolaan}

Untuk menentukan alternatif terbaik dalam pengelolaan sumberdaya laut di PPK Kecamatan Togean, dalam penelitian ini digunakan analisis Multi Criteria Decision Making (MCDM). Dalam analisi ini terlebih dahulu dilakukan pembobotan terhadap kriteria yang paling berpengaruh dalam setiap pengembangan kriteria yang dilakukan. Data yang diperoleh dari hasil pembobotan tersebut akan dianalisis dengan menggunakan Software. Selanjutnya dibuat suatu hirarki (Gambar 8) yang menggambarkan motif pengelolaan sumberdaya yang dilakukan di PPK Kecamatan Togean.

Bentuk hirarki yang disusun menggambarkan bentuk pengelolaan yang sebaiknya dilakukan di wilayah PPK Kecamatan Togean. Pada level pertama, menggambarkan tujuan pengelolaan yang ingin dicapai yaitu pengelolaan sumberdaya laut berkelanjutan. Pada level kedua, menggambarkan kriteria yang menjadi dasar bentuk pemanfaatan yang sebaiknya dilakukan. Pada level ketiga, menggambarkan sub kriteria yang menjadi dasar pengambilan keputusan guna menentukan bentuk kegiatan pemanfaatan sumberdaya. Pada level keempat mengambarkan alternatif bentuk pengelolaan sumberdaya yang sebaiknya dilakukan di masing-masing PPK.

Hasil skenario pengelolaan yang di dapatkan menunjukkan alternatif pengelolaan yang terbaik di PPK Kec. Togean yaitu dengan skenario adaptasi (Gambar 8A) berdasarkan pada ecologi based manajemen (Gambar 8B),dimana ekologi menjadi perhatian utama dari pengelolaan. Kerusakan ekologi dianggap akan memiliki dampak negatif terhadap tatanan perekonomian dan kehidupan sosial masyarakat. Kriteria selanjutnya yang memberikan kontribusi terhadap pengelolaan adalah kriteria ekonomi yang dirasakan sangat mempengaruhi kehidupan masyarakat dan sumberdaya yang ada di PPK khususnya pulau-pulau yang ada aktifitas perekonomiannya seperti $P$. Enam dan P. Tongkabo, sedangkan PPK lainnya tidak memiliki aktifitas ekonomi (P. Mogo, P. Pagempa, P. Kadidiri, P. Kukumbi.

Setelah melihat kontribusi masingmasing kriteria, selanjutnya menjelaskan kontribusi masing-masing atribut terhadap pengelolaan yang akan akan dilakukan di PPK Kec. Togean (Gambar 9). Atribut yang menjadi prioritas dalam pengelolaan PPK di Kecamatan Togean yaitu indeks pantai, degradasi terumbu karang, degradasi mangrove, degradasi lahan terbangun, indeks populasi, keterisolasian, besar kecilnya pasar dan bantuan tunjangan pemerintah. Hal ini bermaksud atribut tersebut menjadi dasar dalam pengambilan kebijakan pengelolaan PPK Kecamatan Togean.

Gambar 8. Skenario pengelolaan PPK Kecamatan Togean

A. Skoring keputusan; B. Prioritas pengelolaan 


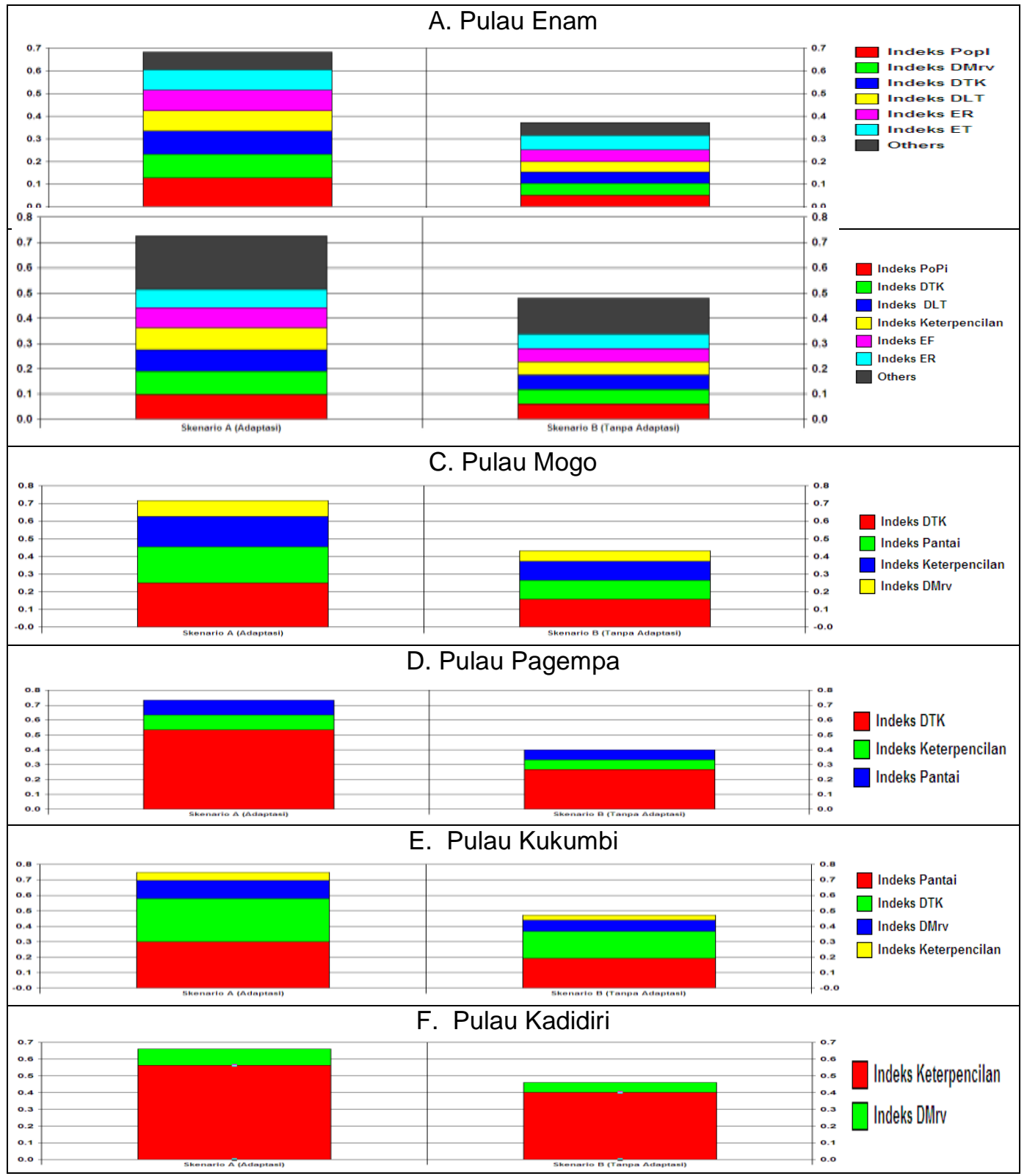

Gambar 9. Skenario pengelolaan pulau-pulau kecil berdasarkan atribut

\section{Kesimpulan}

Kesimpulan yang dapat disarikan pada penelitian ini adalah :

Indeks kerentanan saat ini untuk PPK yang menjadi Studi kajian yaitu Kerentanan tertinggi adalah P. Enam (high vulnerable), P. Tongkabo (medium vulnerable), P. Kukumbi dan P. Mogo (low vulnerable). untuk P. Pagempa dan P. Kadidiri tergolong dalam level non vulnerable.

Bentuk Pengelolaan yang dilakukan untuk PPK yang menjadi objek penelitian yaitu ecological based manajeman, dan Skenario pengelolaan yang dilakukan harus memperhatikan skala prioritas baik itu kriteria maupun atribut dalam menunjang pengelolaan yang berkelanjutan di PPK.

\section{Daftar Pustaka}

Adrianto, L. 2004.Pembangunan dan pengelolaan pulau-pulau kecil yang berkelanjutan (sustainable small islands development and management). In Working Paper Kebijakan Pengelolaan Perikanan dan Wilayah Pesisir Tahun 2004(Eds : Adrianto L). Pusat Kajian Sumberdaya Pesisir dan Lautan, IPB. Bogor. Part-5. 
Adrianto, L. 2005. Evaluasi ekonomi sumberdaya pulau-pulau kecil; sebuah konsepsi ecological economics. In Working Paper Kebijakan Pengelolaan Perikanan dan Wilayah Pesisir Tahun 2005 (Eds : Adrianto L). Pusat Kajian Sumberdaya Pesisir dan Lautan, IPB. Bogor. Part-7.

Adrianto, L., Matsuda, Y. 2002. Developing economic vulnerability índices of environmental disasters in small island región. Environmental Impact Assessment Review 22: 394-414.

Adrianto, L., Matsuda, Y. 2004. Study in assesing econimic vulnerability of small island regions. Environmental Development and Sustainability 6: 317336.

Beller, W., d'ayala, P., Hein, F. 1990. Sustainable Development and Environmental Management of Smal Islandsi. The Partenon Publishing Group, Paris, France, New jersey, USA.

Briguglio, L. 1995. Small island developing states and theier economic vulnerabilities. World Development 23 (9): 1615-1632.

Dahuri, R. 2003. Paradigma Baru Pembangunan Indonesia Berbasis Kelautan. Orasi IImiah Guru Besar Tetap bidang pengelolaan Sumberdaya Pesisir dan Perikanan, Direktorat Jendral Pesisir dan Pulau-pulau Kecil, Direktorat Tata Ruang Laut, Pesisir dan Pulau-pulau Kecil.

Fors, H.C. 2007. Island Status, Country Size and Institutional Quality in Former Colonies. Working Papers In Economics, No 257. SchoolOf Business, Economic and Law, Goteborg University. Goteborg, Sweden.

Hein, P.L. 1990. Economic problem and prospect of small islands In W. Beller, P.d'Ayala and P. Heian (eds). Sustainable Development and Environmental Management of Smal Islands. The Partenon Publishing Group, Paris, France, New jersey, USA. Pp 3544.

Kaly, U.L., Prat, C.R., Mitchell, J. 2004. The Demonstration Environmental VulnerabilityIndex (EVI) 2004. SOPAC Technical Report 304. UNEP, Ireland, Italy, New Zealand and Norway. 323 pp.
Pelling, M., Uitto, J.I. 2001. Small island developing states: natural disaster vulnerability and global change. Environmental Hazard 3: 49-63.

Pratt CR, Kaly UL, and Mitchell J. 2004. Manual: How to Use the Environmental Vulnerability Index (EVI). SOPAC TECHNICAL Report 383, 60 pp; 1 appendix, 2 figures. United Nation Envirinment Programme (UNEP). South Pacific Applied Geoscience Commisison (SOPAC).

Saaty TL. 1991. Pengambilan Keputusan Bagi Para Pemimpin : Proses Hirarki Analitik Untuk Pengambilan Keputusan dalam Situasi yang Kompleks. Seri Manajemen No. 134 (Terjemahan). Jakarta: Pustaka Binaman Pressindo. 